\title{
Study on Mechanism of Shear Swirling Flow Vibration Cementing Improving Displacement Efficiency in Horizontal Well
}

\author{
Ai Chi ${ }^{*}$, , Cui Zhihua ${ }^{1}$, Feng Fuping ${ }^{1}$, Xu Yifan ${ }^{2}$, Cui Zhiheng ${ }^{3}$ and Cui Zhixian ${ }^{4}$ \\ ${ }^{I}$ Key Laboratory of Education Ministry for Enhanced Oil Recovery, Northeast Petroleum University, Daqing, \\ Heilongjiang 163318, China \\ ${ }^{2}$ The Second Oil Production Plant, PetroChina Daqing Oilfield Co., Ltd, Daqing, Heilongjiang 163400, China \\ ${ }^{3}$ The Eighth Oil Production Plant, PetroChina Daqing Oilfield Co., Ltd, Daqing, Heilongjiang 163514, China \\ ${ }^{4}$ The Fourth Oil Production Plant Operating Unit, PetroChina Daqing Oilfield Co., Ltd, Daqing, Heilongjiang 163511, \\ China
}

\begin{abstract}
When horizontal wells cementing, drilling fluid is easy to be held up at the narrow clearance due to casing eccentricity. At the same time, the density difference makes the lighter drilling fluid gather in the upper portion of borehole. Drilling fluid is hard to be displaced cleanly. Shear swirling flow vibration cementing technique is a new effective cementing technique, which can improve the cementing quality in several ways. On the one hand, shear swirling flow vibration cementing technique makes the annular fluid swirling flow. The circumferential velocity increases a circumferential shear stress for borehole wall, making it easy to carry drilling fluid near the wall and scour mud cake on the wall. Especially for the displacement at narrow clearance caused by the casing eccentricity in horizontal well, the effect will be more obvious. On the other hand, shear swirling flow vibration cementing technique makes the casing string periodically eccentric revolution. It changes the conventional pressure distribution and forms pressure difference on the annular cross section. The pressure at wide clearance is greater than that at narrow clearance, which is advantageous for the fluid flowing from wide clearance to narrow clearance and makes drilling fluid at the narrow clearance displaced effectively. In the paper, it analyzed the mechanism of shear swirling flow vibration cementing improving displacement efficiency from swirling flow and vibration two angles.
\end{abstract}

Keywords: Displacement efficiency, horizontal well, swirling flow, vibration.

\section{INTRODUCTION}

Cementing is an important link in the process of building oil and gas wells. Improving cementing quality is crucial to achieve long-term stable yield. But cementing is always a difficult problem for oilfield, especially horizontal wells cementing with the improvement of reservoir producing degree and the progress of drilling technology in recent years. In the process of drilling, drilling fluid would form mud cake on the wall. If the mud cake is not removed when cementing, it would seriously affect the cementing quality. Experiments proved that vibration cementing technique can improve the cementing quality in several ways. Vibration can improve the properties of the fluid, improve the displacement efficiency, improve the cementing strength, shorten the cement setting time, and reduce or even eliminate the static shear force of slurry. So it is a new promising cementing technique. Vibration cementing devices at home and abroad can be divided into hydraulic impulse type, mechanical type, magnetostriction type, piezoelectric ceramic type, audio frequency vibrating type, annulus

*Address correspondence to this author at the Key Laboratory of Education Ministry for Enhanced Oil Recovery, Northeast Petroleum University, Daqing, Heilongjiang 163318, China; Tel: 04596503073;

E-mail: hi891012hi@126.com impulse type, etc. At present, the most widely designed and used device is the hydraulic impulse vibration type. The paper mainly introduced the shear swirling flow vibration cementing downhole tool and the mechanism of improving displacement efficiency in horizontal wells.

\section{THE SHEAR SWIRING FLOW VIBRATION CEMENTING DOWNHOLE TOOL}

The shear swirling flow vibration cementing downhole tool is mainly composed of diversion outlets and eccentric cascades, as shown in Fig. (1). The diversion outlet exists inclination angle, making the fluid change flow direction and

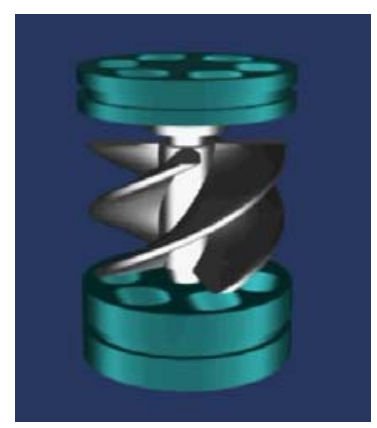

Fig. (1). The structure of downhole eccentric cascade. 
impact eccentric cascades. Under the impact action of fluid, cascades revolve at high speed. At the same time, there is an eccentric block installed on one side of the cascade, making a direction changing force applied at the bottom of casing string, and making it periodically eccentric revolution.

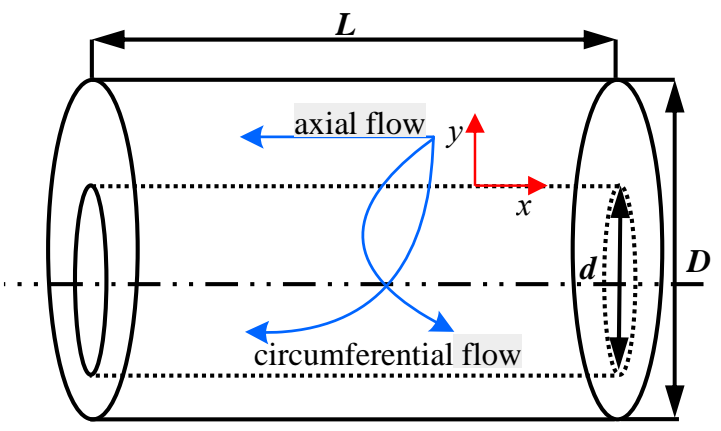

Fig. (2). The annular flow field in horizontal well.

\section{THE MECHANISM OF SWIRLING FLOW IMPROVING DISPLACEMENT EFFICIENCY}

When shear swirling flow vibration cementing, annular flow field is swirling flow field, which can be decomposed into axial flow and circumferential flow, as shown in Fig. (2). The circumferential velocity of swirling flow increases a circumferential shear stress for borehole wall, which makes for carrying drilling fluid near the wall and scouring mud cake on the wall. Especially for the displacement at narrow clearance caused by the casing eccentricity in horizontal well, the effect will be more obvious. The carrying and scouring action of circumferential flow and the displacement action of axial flow work together, which can greatly improve the displacement efficiency $[1,2]$.

Wall shear stress produced by axial velocity:

$\tau_{w}=\Delta P(D-d) /(4 L)$

$\Delta P=\frac{4 \rho v^{2} f}{(D-d)} L$

where, $\tau_{\mathrm{w}}$ is the wall shear stress, $\mathrm{Pa} ; D$ is the borehole diameter, $\mathrm{m}$; $d$ is the external diameter of casing, $\mathrm{m} ; \Delta P$ is the pressure drop, $\mathrm{MPa} ; L$ is the cementing length, $\mathrm{m} ; \rho$ is the density of cement slurry, $\mathrm{g} \mathrm{cm}^{-3} ; f$ is the friction coefficient; $v$ is the axial velocity, $\mathrm{m} \mathrm{s}^{-1}$.

The maximum circumferential velocity is about $0.8 h_{\mathrm{c}}$ distance from the inner wall. The annulus can be divided into inner zone and outer zone with $0.8 h_{\mathrm{c}}$ distance from inner wall as the boundary $[3,4]$. The inner zone is $0 \sim 0.8 h_{\mathrm{c}}$. The outer zone is $0.8 h_{\mathrm{c}} \sim h_{\mathrm{c}}$. According to Table $\mathbf{1}$, finally the inner wall shear stress and outer wall shear stress produced by circumferential velocity:

$\tau_{i w}=0.8 k\left[\frac{\bar{u}_{\theta}(2 n+1)}{n\left(\frac{3 n+1}{n+1}+0.25\right)\left(0.8 h_{c}\right)^{\frac{2 n+1}{n}} h_{c}}\right]^{n}$

$\tau_{o w}=0.2 k\left[\frac{\bar{u}_{\theta}(2 n+1)}{n\left(\frac{3 n+1}{n+1}+0.25\right)\left(0.8 h_{c}\right)^{\frac{2 n+1}{n}} h_{c}}\right]^{n} 4^{n+1}$

where, $h_{c}$ is the width of annular clearance.

The basic parameters: external diameter of casing 139.7 $\mathrm{mm}$, borehole diameter $230 \mathrm{~mm}$, eccentric distance $15 \mathrm{~mm}$, consistency coefficient $0.17 \mathrm{Pas}^{\mathrm{n}}$, flow index 0.89 (powerlaw mode). Numerical simulation method was used to get the circumferential velocity of annulus fluid at different revolving speed, as shown in Fig. (3).

Combined with the circumferential velocity of annulus fluid by numerical simulation, calculate the wall shear stress using formula (1) (4), as shown in Table 2.

From Table 2, with the increase of revolving speed, the circumferential wall shear stress produced by circumferential velocity at wide and narrow clearance increases. Moreover, the maximum circumferential shear stress is at the external boundary of narrow clearance. The circumferential wall shear stress at narrow clearance is greater than that at wide clearance, which makes drilling fluid at the narrow clearance displaced effectively and improves the displacement

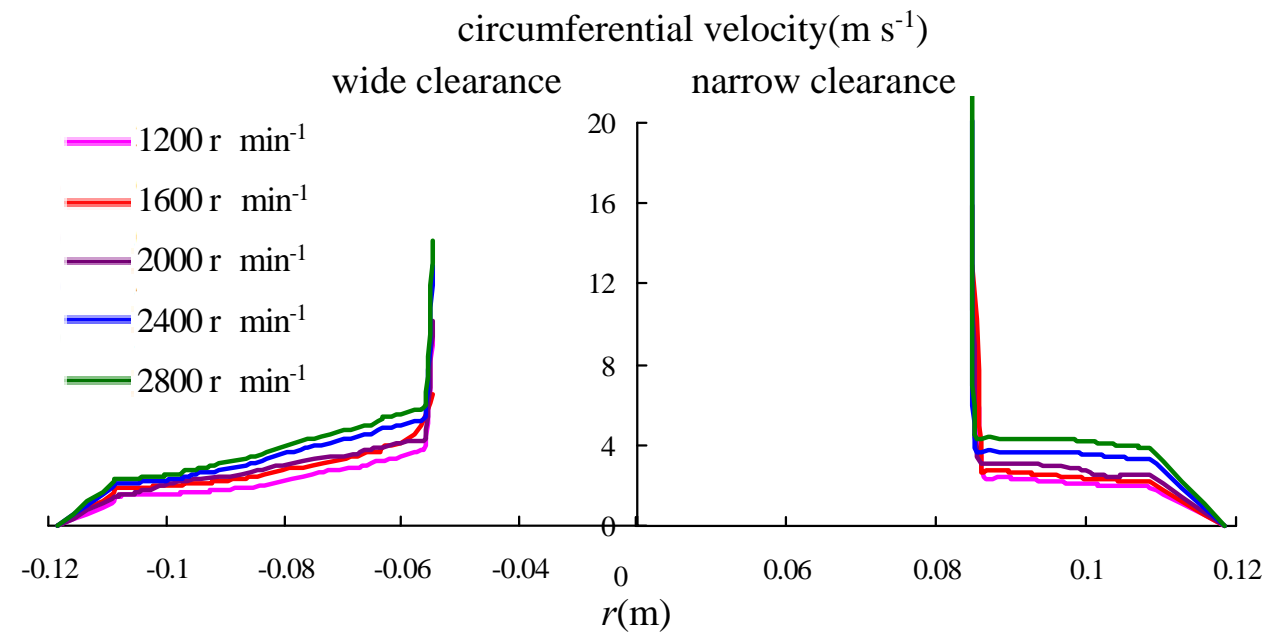

Fig. (3). The circumferential velocity of annulus fluid at different revolving speed $15 \mathrm{~mm}$ eccentric distance. 
Table 1. Fluid mechanics analysis under circumferential velocity.

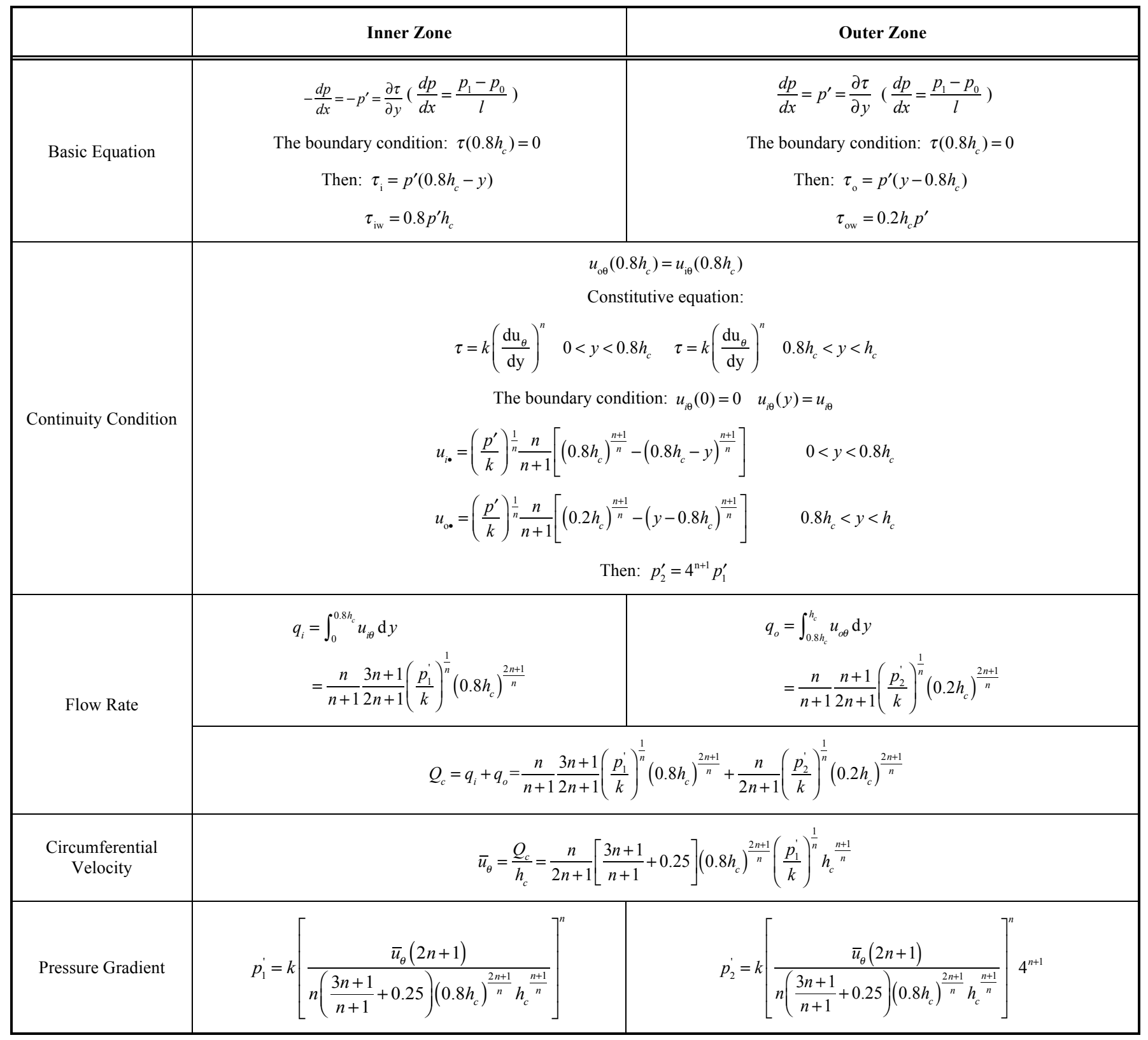

efficiency. The external circumferential wall shear stress is larger than the internal circumferential wall shear stress, the average 3.43 times larger, which is helpful to remove drilling fluid near the wall and scour mud cake.
As shown in Fig. (4), the compressive, dense and solid of mud cake are collectively referred to as true mud cake. The shear strength of solid of mud cake is $3.0 \sim 8.0 \mathrm{kPa}$. The shear strength of dense of mud cake is $0.1 \sim 3.0 \mathrm{kPa}$. The

Table 2. The wall shear stress at different revolving speed.

\begin{tabular}{|c|c|c|c|c|c|}
\hline \multirow{2}{*}{$\begin{array}{c}\text { Axial Wall } \\
\text { Shear Stress (Pa) }\end{array}$} & $\begin{array}{c}\text { Revolving } \\
\text { Speed (r min }\end{array}$ & \multicolumn{2}{|c|}{ Internal Circumferential Wall Shear Stress (Pa) } & \multicolumn{2}{|c|}{ External Circumferential Wall Shear Stress (Pa) } \\
\cline { 3 - 6 } & & Narrow Clearance & Wide Clearance & Narrow Clearance & Wide Clearance \\
\hline \hline 15.27 & 1200 & 3.41 & 0.34 & 11.71 & 1.16 \\
\hline 15.27 & 1600 & 3.85 & 0.41 & 13.23 & 1.39 \\
\hline 15.27 & 2000 & 4.33 & 0.43 & 18.14 & 1.49 \\
\hline 15.27 & 2400 & 5.28 & 0.49 & 20.98 & 1.67 \\
\hline 15.27 & 2800 & 6.11 & 0.53 & 1.82 \\
\hline
\end{tabular}


shear strength of compressive of mud cake is from $0.02 \sim 0.1$ $\mathrm{kPa}$. The traditional cementing can only remove false mud cake [5-7]. The shear swirling flow vibration cementing not only can remove false mud cake, but also can scour compressive of mud cake. The smaller the thickness of mud cake, the higher the bonding strength. Therefore, the shear swirling flow vibration cementing can effectively improve the cementing quality.

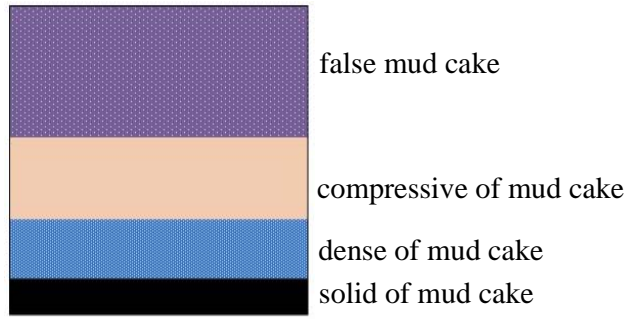

Fig. (4). The layered structure of mud cake.

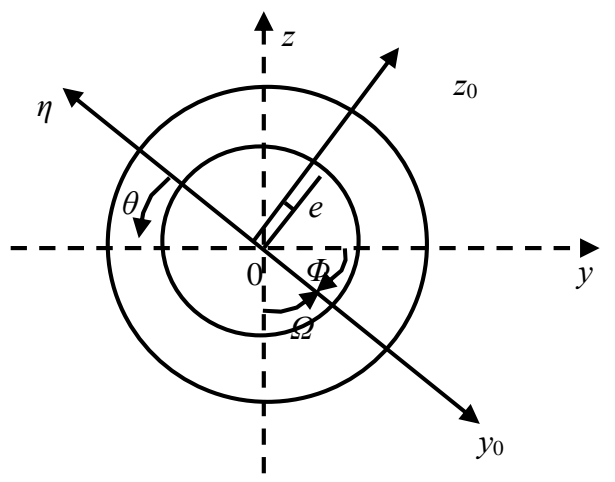

Fig. (5). The revolving of casing in borehole.

\section{THE MECHANISM OF VIBRATION IMPROVING DISPLACEMENT EFFICIENCY}

As shown in Fig. (5), the position of casing centre is $e, \Phi$ at any moment. $\Omega$ is the angular velocity of casing revolving [8].

Motion equation of drilling fluid:

$\frac{1}{R} \frac{d p}{d \theta}=\mu \frac{\partial^{2} u}{\partial \eta^{2}}$
$\frac{1}{R} \frac{\partial u}{\partial \theta}+\frac{\partial v}{\partial \eta}=0$

Continuity equation:

$\frac{\partial v_{r}}{\partial r}+\frac{1}{r} \frac{\partial v_{\theta}}{\partial \theta}=0$

In the center of casing, circumferential disturbance velocity and radial disturbance velocity are:

$u_{c}=e \Omega \mathbf{n} v_{c}=-e$

In polar coordinate, the boundary conditions in flow field are:

$\left.u\right|_{\eta=0}=\Omega R+u_{c} \cos \theta-v_{c} \sin \theta=\bar{u}$ $\left.v\right|_{\eta=0}=u_{c} \sin \theta+v_{c} \cos \theta=\bar{v}$

External boundary conditions for casing are:

$\left.u\right|_{\eta=h}=0$

$\left.v\right|_{\eta=h}=0$

where,

$$
\begin{aligned}
& h=\delta(1-\varepsilon \cos \theta) \\
& \varepsilon=e / \delta
\end{aligned}
$$

Using the motion equation, boundary conditions and assuming that drilling fluid is continuous, the average pressure difference is:

$$
\begin{aligned}
p-p_{0}= & 12 \mu R^{2} \frac{\varepsilon\left(\frac{u_{c}}{e}+\frac{\Omega}{2}\right)}{\delta^{2}\left(2+\varepsilon^{2}\right)} \frac{(2+\varepsilon \cos \theta) \sin \frac{\theta}{2}}{(1+\varepsilon)^{2}} \\
& -\frac{v_{c}}{2 \varepsilon^{2} \delta^{3}}\left(\frac{1}{(2+\varepsilon \cos \theta)^{2}}-\frac{1}{(2+\varepsilon)^{2}}\right)
\end{aligned}
$$

where, $p$ is the average pressure at any circumferential angle; $p_{0}$ is the average pressure at narrow clearance. The pressure distribution on annular cross section under different revolving speed is shown in Fig. (6). The narrow clearance corresponds to the circumferential angle $0^{\circ}$. The wide clearance corresponds to the circumferential angle $180^{\circ}$. From Fig. (6), the pressure distribution shows wave form under the action of casing revolving. The unstable wave form of pressure will lead to the instability of drilling fluid. The pressure at narrow clearance is minimum. The pressure at wide clearance is maximum. With the increase of clearance width, the average pressure difference increases.

\section{CONCLUSION}

(1) The shear stress at narrow clearance is greater than that at wide clearance, which is helpful for drilling fluid at narrow clearance displaced effectively and improving the displacement efficiency.

(2) The external wall shear stress is larger than the internal wall shear stress, which makes for scouring mud cake and increasing the second interface cementing quality.

When shear swirling flow vibration cementing, there is a pressure difference on the cross section. The pressure at wide clearance is greater than that at narrow clearance, which is advantageous for the fluid flowing from wide clearance to narrow clearance and makes drilling fluid at the narrow clearance displaced effectively.

(4) With the increase of revolving speed, the average pressure difference between wide clearance and narrow clearance increases, making the drilling fluid at the narrow clearance displaced easily. 


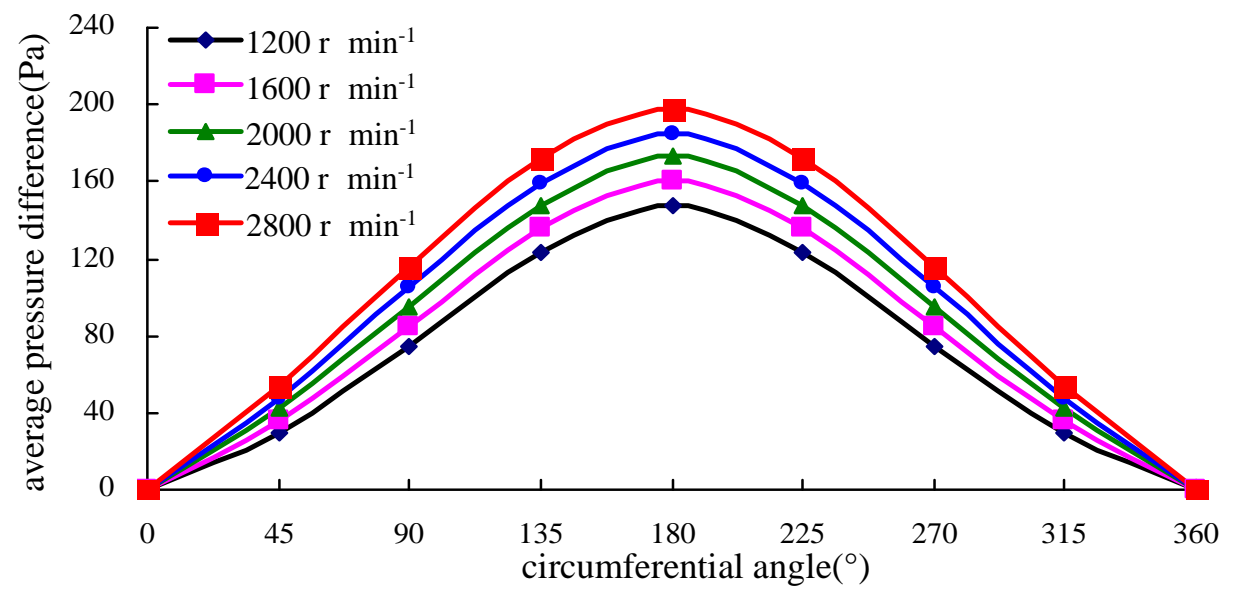

Fig. (6). The pressure distribution on annular cross section under different revolving speed $15 \mathrm{~mm}$ eccentric distance.

\section{CONFLICT OF INTEREST}

The authors confirm that this article content has no conflict of interest.

\section{ACKNOWLEDGEMENTS}

The support of the National Natural Science Foundation of China (Grant No. 51404071) is gratefully acknowledged.

\section{REFERENCES}

[1] Zheng, Y.G. A study of displacement mechanism during cementing in eccentric annulus. Nat. Gas Industry, 1995, 15(3), 46-50.

[2] Zheng, Y.G. Displacement mechanism of laminar flow cementing in deviated wells. Acta Petrol. Sin., 1995, 16(4), 133-138.
[3] Szabo, P.; Hassager, O. Simulation of free surfaces in 3-D with the arbitrary Lagrange-Euler method. Int. J. Num. Methods Eng., 1995, 38, 717-734.

[4] Bittleston, S.H.; Ferguson, J.; Frigaard, I.A. Mud removal and cement placement during primary cementing of an oil well: laminar nonnewtonian displacements in an eccentric annular hele-shaw cell. J. Eng. Math., 2002, (43), 229-253.

[5] Liu, C.J.; Liu, X.L.; Liu, N.Z.; Wang, T. Research on raising slurry displacing efficiency in a slim hole. Nat. Gas Industry 2003, 23(2), 46-49.

[6] Yang, J.B.; Deng, J.M.; Li, Z.H.; Chen, Y. Effect of density difference on displacement efficiency during low-rate cementing. Petrol. Drill. Technol., 2007, 35(5), 80-81.

[7] Feng, F.P.; Ai, C.; Peng, W.Y. Effect of casing eccentricity on displacement in horizontal well. Oil Drill. Prod. Tech., 2011, 33(3), 13-15.

[8] Newman, K.; Wojtanowicz, A.; Gahan, B.C. Cement pulsation improves gas well cementing. World Oil, 2001, July, 1-5.

(c) Chi et al.; Licensee Bentham Open.

This is an open access article licensed under the terms of the Creative Commons Attribution Non-Commercial License (http://creativecommons.org/licenses/by-nc/3.0/) which permits unrestricted, non-commercial use, distribution and reproduction in any medium, provided the work is properly cited. 